\title{
Predicting Managerial Coaching Behaviors by the Big-Five Personality Traits
}

\author{
Guohai Chen, Wen Huang, Yuwen Tang \\ School of Management, Guangdong University of Foreign Studies, Guangzhou, China \\ Email: mypeer2002@hotmail.com
}

Received October 9, 2013; revised November 12, 2013; accepted November 20, 2013

Copyright (C) 2013 Guohai Chen et al. This is an open access article distributed under the Creative Commons Attribution License, which permits unrestricted use, distribution, and reproduction in any medium, provided the original work is properly cited. In accordance of the Creative Commons Attribution License all Copyrights (C) 2013 are reserved for SCIRP and the owner of the intellectual property Guohai Chen et al. All Copyright (C) 2013 are guarded by law and by SCIRP as a guardian.

\begin{abstract}
The research of this paper aims to construct a Chinese Managerial Coaching Behavior Inventory and examine the correlations of managerial coaching behaviors and the Big-Five personality traits. In Study One, 196 managers from several companies filled out a self-complied Managerial Coaching Behavior Inventory based on Noer's Triangle Coaching Model and Social Desirability Scale. A Chinese Managerial Coaching Behavior Inventory with 46 items was developed, including three subscales (namely, Accessing, Challenging, and Supporting) with high Cronbach alphas (all $>0.85$ ). In Study Two, this inventory and the NEO Five-Factor Inventory were administered to 175 managers. Analysis showed that scores on the three managerial coaching behaviors Accessing, Challenging, and Supporting were positively related to those on Extraversion, Openness to Experience, Agreeableness, and Conscientiousness, while they were negatively related to Neuroticism. Big-Five personality traits (particularly Extraversion, Openness to Experience, and Conscientiousness) were good predictors of managerial coaching behaviors. Implications for human resource management and enterprise coaching are discussed.
\end{abstract}

Keywords: Managerial Coaching Behavior; Inventory; Development

\section{Introduction}

In recent years, coaching has become an essential part of managing and leading people [1] and the idea that managers should be coaches has been consistently advocated by researchers and practitioners [2-5]. So far, researchers have been mainly interested in discussing and exploring the definitions, functions or efficacy, dimensions, measurements, and improvements of coaching and its correlation with other variables. McLean et al. [6] defined managerial coaching behaviors as a managerial practice which shows effective coaches' characteristics including open communication, team work, evaluating employees through work and tolerance of uncertainty. A number of empirical studies have shown the effectiveness of coaching in organizations [5,7-10]. For example, Ellinger et al. [7-8] have empirically demonstrated the positive impact of coaching behaviors on employee job satisfaction and productivity. Sulivan [9] found that executive coaching is an effective tool in the enhancement of emotional intelligence competencies in executives. Chen and Zhang [5] also found that executive coaching has a positive influence on job satisfaction and a negative influence on turnover intention. Kim's [10] investigations suggested that managerial coaching has a direct impact on employee satisfaction with work and role clarity and an indirect impact on satisfaction with work, career commitment, job performance, and organization commitment. Since managerial coaching has become increasingly popular in organizations [10] and effective coaching needs appropriate coaching skills, the phrases "coaching behavior", "managerial coaching behavior", "coaching ability", "coaching competence", and "coaching skill" have appeared in the literature, but no agreement has been reached on definitions.

There are a variety of coaching skills/behaviors identified and categorized by researchers [1,7,10-11] As Ellinger, Hamlin, and Beattie [1] stated, the requisite coaching skills described in the conceptual literature usually include listening skills, analytical skills, interviewing skills, effective questioning techniques, and observation, while typical coaching behaviors usually con- 
sist of giving and receiving performance feedback, communicating and setting clear expectations, and creating a supportive environment conducive to coaching. Although there are different concrete managerial coaching behaviors, Hamlin, Ellinger, and Beattie [1] concluded that they share a common essence. They found that most common coaching behaviors include those associated with "empowering" (including removing obstacles to learning, framing questions to facilitate development, holding back on the answer), and "facilitating" (including providing feedback, communicating expectations, and talking issues through). Lam [11] classified managerial coaching behaviors into four categories: provide feedback or gain feedback from subordinates; offer subordinates resources and information; encourage, support and recognize subordinates' learning and development; offer personalized coaching intervention to subordinates. Kim [10] categorized the multitude of coaching behaviors in the literature into six clusters of meaning as follows: a) questioning; b) listening; c) advising; d) empowering and goal setting; e)advocating; and f) followthrough.

Measures of coaching behaviors/skills have been emerging in recent years, such as the Mentor Scale [12], Goalfocused Coaching Skills Questionnaire [13], Coaching Behaviors Instrument [6], and Coaching Behaviors Inventory $[14,15]$. There are compelling needs to validate conceptual and empirical measures or inventories of coaching behaviors/skills for future research and coaching practice.

Particularly, Noer $[14,15]$ put forward the Triangle Coaching Model which conceptualizes the process of coaching as a client-centered, helping relationship with three essential dimensions: accessing, challenging, and supporting. Correspondingly, the Coaching Behaviors Inventory with 30 self-assessment items was developed to measure the three dimensions of coaching behaviors. Accessing refers to the use of analytical processes that lead to measurements and goal-setting, including five components: data gathering, gap analysis, goal setting, measurement, and feedback. Challenging refers to stimulating the person being coached to develop concrete plans to meet desired objectives, including four components: confronting, focusing/shaping, reframing, and empowering/energizing. Supporting refers to creating an interpersonal context that facilitates trust, openness, respect and understanding, including five components: attending, inquiring, reflecting, affirming, and airtime. Using the inventory and comparing managerial coaching behaviors of Saudi Arabian with US managers, Noer [15] found Saudi managers exhibited less overall variance as a group in their coaching behaviors, and they exhibited significantly more supporting and challenging behaviors than their American counterparts. In terms of accessing behaviors, no differences were observed between the two samples. Noer [15] reported that Cronbach's alpha reliability coefficients for Assessing, Challenging, and Supporting were $0.81,0.79$, and 0.67 , respectively.

A number of researchers and practitioners have contended that coaching behaviors or skills are teachable and can be improved by learning [16]. Marsh [16] found that coaching skills among managers are a prerequisite for coaching results and such skills are teachable. Wangsgard revealed that the frequency and efficacy of coaching behaviors can be improved and increased in a relatively short period of time with a high performance coaching course.

Concerning the role of personality in coaching, personality measures are considered useful tools for coaching [17-20]. As Carr et al. [19] stated, personality instruments can be used in coaching on two levels: 1) for coaches to understand themselves better and to enhance their own effectiveness, and 2) to help coaches make sense of their patterns of behavior and meet their coaching objectives. An assessment of personality can be an excellent place to start coaching [20]. By detecting dysfunctional personality characteristics with personality measures, coaching does not endeavor to "change" personality but rather utilizes an understanding of a coachee's personality traits to facilitate behavioral change in certain contexts [21,22]. Although quite a number of empirical studies have revealed that personality traits are good predictors of work-related behaviors [23-25], relatively few empirical studies such as Stewart et al.'s [26] study have been found on the relationship between personality and coaching behaviors/skills.

Regarding personality measures, the Big Five Factor Model has been widely accepted and utilized to assess personality traits among normal people in the past several decades $[23,27]$. The five primary personality factors are usually described as a) Neuroticism, b) Extraversion, c) Openness to experience, d) Agreeableness, and f) Conscientiousness [27]. Little is known about the relationship between the Big-Five personality traits and coaching behaviors/skills. One aim of the present research is to explore the correlations of the Big-Five personality traits with coaching behaviors/skills.

Coaching has been gradually introduced into business sectors in China in recent years. However, empirical research and theory construction in this field are far behind coaching practice in China. Few empirical studies on coaching are found in current Chinese literature [5,28]. While improving coaching skills/behaviors with courses is becoming a common practice of coaching in China, coaching efficacy usually remains unknown with no empirical measurements with appropriate assessment tools. Therefore, it is imperative to develop a Chinese Managerial Coaching Behavior Inventory for such a purpose, 
which is the main aim of this research.

\section{Conceptual Framework and Hypotheses}

In order to construct and develop a Chinese Managerial Coaching Behaviors Inventory, we borrowed the Coaching Triangle Model (see Figure 1) posited by Noer $[14,15,29]$ as the conceptual framework of this research. There are three equally important dimensions (namely Supporting, Assessing, and Challenging) to the clientcentered coaching relationship. Each of the three dimensions is made up of four or five behavioral components. Overuse of one dimension at the expense of the other two results in unintended and has unhealthy consequences [14,29].

There are three reasons for us to select Noer's Coaching Triangle Model as the theoretical framework (see Figure 1). Firstly, as Noer [14] stated that Supporting, Assessing, and Challenging are the core dimensions of coaching, this model covers most of the basic coaching skills and coaching behaviors mentioned in the literature [6]. Secondly, the idea of balanced use of each dimension of coaching behaviors in this model is quite consistent with the Confucius doctrine of the mean [30]. Such a model seems to be more recognizable and acceptable in the Chinese context from a cross-culture perspective. Finally, as Noer [15] demonstrated, his Managerial Coaching Behaviors Inventory based on this model can be utilized to measure the coaching behaviors of Saudi managers at the beginning of their coaching skills workshop, assuming that managers consciously or unconsciously exhibit coaching behaviors in their daily interactions with subordinates, even if they may not know what coaching is. Since few companies implement a coaching culture currently in the Chinese context and most managers lack the knowledge and skills of coaching, a Chinese Managerial Coaching Behaviors Inventory based on this model may be used widely to assess managers' coaching behaviors for coaching skills workshop or oneto-one coaching practice.

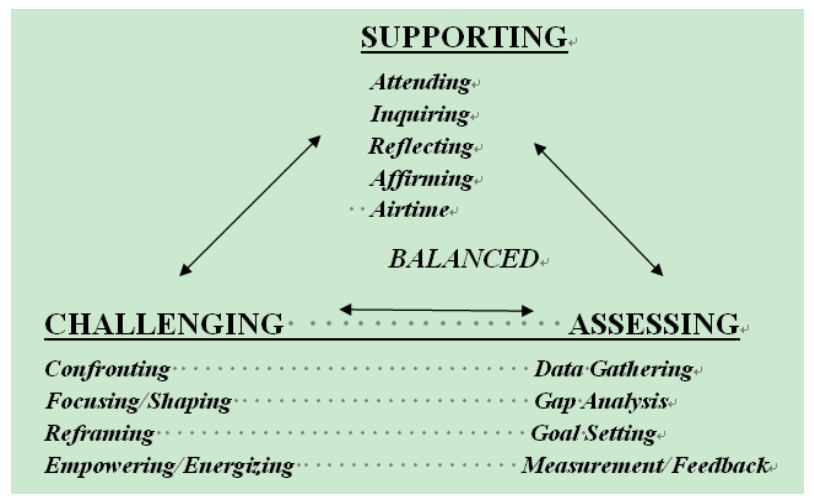

Figure 1. The coaching triangle (sources: Noer, 2005A, 2005B, 2007).
After reviewing previous literature on coaching behavior/skill [13,15-16], we contend that managerial coaching behaviors overlap with effective leader/managerial behaviors to some extent, since managerial coaching behaviors are observable, measurable, teachable, actionable, and effective leader/managerial behaviors. Managerial coaching behaviors are good predictors of high job performance $[2,3,8,10]$. Based on previous findings that the Big-Five personality traits are good predictors of work-related and other behaviors [31-36], we contended that the Big-Five personality traits are important predictors of managerial coaching behaviors. Previous findings have also revealed that the Big-Five personality traits are good predictors of job performance [37,38]. Thus, we can depict the interactive relationship among the Big-Five personality traits, coaching behaviors, and job performance as in Figure 2. In this paper, we will examine the relations between the Big-Five personality traits and coaching behaviors.

We made four hypotheses based on Figure 2 and previous findings. Since higher scores on Agreeableness in the Big-Five taxonomies show altruism, sympathy, helpfulness, and cooperativeness [27], we hypothesize that Agreeableness is positively related to Supporting behaveiors of coaching (H1). Since higher scores on Openness to Experience reflect an active imagination, aesthetic sensitivity, attentiveness to inner feelings, preference for variety, and intellectual curiosity, we hypothesize that Openness to Experience is positively related to Challenging behaviors of coaching (H2). Since Conscientiousness is generally and positively related to good behaviors and high job performance factors such as honesty but negatively related to bad behaviors such as alcohol consumption, accident involvement, and counterproductive work behaviors $[33,35,36,38]$, we assume that Conscientiousness is positively related to all the three dimensions of coaching behaviors (namely Supporting, Assessing, and Challenging) (H3). Since Neuroticism is usually negatively related to high job performance

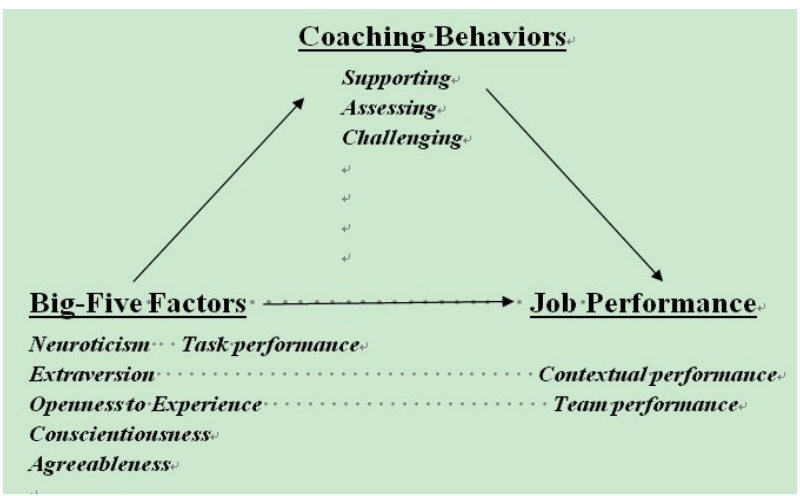

Figure 2. Relationship among Big-Five personality traits, coaching behaviors, and job performance. 
$[37,38]$, we assume that Neuroticism is negatively related to all the three dimensions of coaching behaviors (namely Supporting, Assessing, and Challenging) (H4).

\section{Study One: Development of the Chinese Managerial Coaching Behavior Inventory}

\subsection{Preliminary Considerations}

There are four specific considerations in developing the Chinese Managerial Coaching Behavior Inventory. Firstly, as mentioned before, we assume that managers naturally exhibit more or less of the different coaching behaviors in their daily work, which allow us to collect data in a variety of company settings. All the participants in the present research knew little about coaching nor had received a coaching workshop.

Secondly, although we adopted Noer's Coaching Triangle Model as the theoretical framework (see Figure 1), we did not directly translate the Managerial Coaching Behavior Inventory [29] and validate it in the Chinese context for the following reason: the third author (Mr. Tang) contacted the original author Dr. David M. Noer by e-mail and no reply came back to us. As such, we did not get the full copy of Noer's [29] inventory until we began to revise this paper. The first author (Dr. Chen) contacted Dr. Noer again during revision of this paper and Dr. Noer agreed to send us a copy of the inventory for reference.

Thirdly, managerial coaching behaviors are said to be "good" or "effective" behaviors that managers wish to possess. When managers know something about coaching, specifically after managers attend a coaching workshop course, they are likely to fake "good" in filling an inventory on managerial coaching behaviors. So a social desirability scale was utilized to improve the process of item selection when developing the Chinese Managerial Coaching Behavior Inventory.

Finally, it has been noticed that scholars may utilize factor analysis techniques to test the construct validity of a coaching behaviors inventory [6,11]. However, Dr. Noer did not use factor analysis techniques in developing his inventory [14,29]. We agreed on this point since the three managerial coaching dimensions (Accessing, Challenging, and Supporting) in Noer's Coaching Behaviors Triangle Model reflect an intrinsically highly relevant, overlapped, and inter-correlated managerial process. Moreover, factor analysis techniques also have limitations in identifying factor structure in some settings such as sampling issues [39].

\subsection{Item Generation}

In developing the Chinese Managerial Coaching Behavior Inventory, we employed the construct-based scale construction approach recommended by Jackson [40].
The authors discussed Noer's Coaching Triangle Model and fully understood the exact definitions and meanings of behavioral components for each of the three dimensions (Accessing, Challenging, and Supporting) [15]. Based on previous literature on managerial coaching behaviors [6,11,14-15], an initial 70 items were generated for the inventory through brainstorming. After further discussion and comparison, 62 items remained by deleting 8 overlapping and ambiguous items. Five managers who are part-time MBA students at Guangdong University of Foreign Studies were invited to read a brochure on Noer's Coaching Triangle Model and definitions of behavioral components for each of the three dimensions. Afterwards, they were invited to give comments on the 62 items. They suggested keeping all the 62 items although 4 of the items needed rewording. As a result, the inventory consisted of 62 items for the three dimensions. The Assessing dimension contained 20 items ( 5 items for each of the 4 behavioral components: data gathering, gap analysis, goal setting and measurement/feedback), The Challenging dimension contained 22 items $(6,5,5,4$ items respectively for the following behavioral components: confronting, focusing/shaping, reframing, empowering/energizing), and the Supporting dimension contained 22 items $(5,4,5,5,3$ items respectively for the following behavioral components: attending, inquiring, reflecting, affirming and airtime).

\subsection{Item Refinements}

In order to further refine the items of this inventory, the self-compiled inventory with 62 items and a social desirability scale were administered to 196 managers (125 men, 70 women, and 1 unknown; Mage $=33.7$ years, $S D$ $=8.0$ ) from 5 firms in Guangzhou, P. R. China. The five companies were: 3 state-owned listed companies (1 in the airport sector, 2 in real estate), 1 state-owned company (in logistics), and 1 private enterprise (in foreign trade). They were selected by convenience since the first author had strong contacts with these companies. The Social Desirability Scale employed in the present study is described as follows:

The Social Desirability Scale aims to assess one's social desirability and high scorers tend towards social desirability but do not necessarily reflect the real situation. Respondents rate each statement on a 5-point Likert scale ranging from $1=$ "strongly disagree" through $5=$ "strongly agree". It contains 10 items in which 8 items came from previous research findings $[41,42]$, and one sample item is "I'm born with the ability to influence others." The other two items have their origin in previous research results $[43,44]$, namely "I like almost all the people" and "I can always achieve my goal in life.", which are consistent with the social desirability scale developed by Cheung et al. $[41,42]$. The Cronbach alpha 
reliability coefficient of the 10-item Social Desirability Scale is 0.71 in the present sample.

The process of retaining items in the inventory with three criteria is as follows: First, to increase the discriminability of each item, standard deviation for each item should be greater than 1 [40] and no items with their standard deviations less than 1 were removed. Second, to reduce faking good responses, 15 items were removed for correlation coefficients with the Social Desirability Scale scores greater than 0.3 . Third, because the items in each of the subscales still possessed some redundancy in their semantic content, the corrected item-total correlations were employed to select items and this procedure resulted in 4 items being removed from the inventory for corrected item total correlations less than 0.30 with their designated subscales.

Finally, 11, 15, and 20 items were retained for Assessing, Challenging, and Supporting dimensions, respectively. Therefore, the Chinese Managerial Coaching Behaviors Inventory consists of 46 items in total. Corrected item total correlations for Assessing ranged from 0.39 to 0.69 , for Challenging from 0.50 to 0.71 , and for Supporting from 0.36 to 0.63 . Cronbach's alpha reliability coefficients for Assessing, Challenging and Supporting were $0.87,0.91$, and 0.92 , respectively, indicating high internal consistency of each subscale.

\subsection{Further Data Analysis}

Descriptive statistics (means and standard deviations) and Pearson correlation coefficients among the three dimensions are shown in Table 1. The Pearson inter-correlation coefficients among the three dimensions of the managerial coaching behaviors (assessing-challenging; assessing-supporting; challenging-supporting) were 0.87 , 0.80 and 0.88 , respectively (all $p<0.01$ ), indicating each subscale is highly correlated with each other. No signifycant differences in each dimension (Assessing, Challenging, and Supporting) were significant based on sex and age.

\section{Study Two: Relations of Scores on the Big-Five Personality Traits with Managerial Coaching Behaviors}

\subsection{Participants}

The participants were 175 managers (117 men, 56 women, and 2 missing; $M$ age $=32.58, S D=7.79) .32$ of them were part-time MBA students of Guangdong University of Foreign Studies. The rest were managers from 4 firms (1 in manufacturing, 1 in logistics, 1 in retail selling, and 1 in insurance). They were invited to complete the Chinese Managerial Coaching Behavior Inventory and Chinese translation of the NEO Five-Factor Inventory. Each participant was also invited to report sex and age. MBA participants filled the questionnaire in pencil and paper during a break in one course while other participants completed the word-format questionnaire on computers and emailed it back to the third author.

\subsection{Measures}

Chinese Managerial Coaching Behaviors Inventory. This consists of the three dimensions of coaching behaviors (Supporting, Assessing, and Challenging). The supporting subscale consists of 20 items and one sample item is "I talk to my subordinates with non-fearful body language, a friendly voice, and natural eye contacts."; the Assessing subscale consists of 11 items and one sample item is "I often collect remarks or comments about my subordinates from other staff."; and the Challenging subscale consists of 15 items and one sample item is "I often discuss with my subordinates perceptions of their work and help them surpass self-handicapping." Forthe present sample, Cronbach's alpha reliability coefficients were 0.87, 0.91, and 0.92 for Assessing, Challenging, and Supporting, respectively, indicating high internal consistency of each subscale.

The NEO Five-Factor Inventory. This inventory, developed by Costa and McCrae [27], was employed in the present study. It is a short form of test with 60 items to assessthe five factors of personality with each of the five factors being measured by 12 items. McCrae and Costa (1989) reported that Cronbach alphas for each subscale of the five factors were 0.70 or above. Participants rated items on a 5-point Likert scale ranging from "1" (Strongly disagree) to "5" (Strongly agree).The present study adopted a Chinese translation of this inventory. Cronbach's alpha reliability coefficients in previous studies [45-47] were a bit low for the Openness to Experience subscale, ranging from 0.52 to 0.56 , while those for the other four subscales ranged from 0.64 (Agreeableness) to 0.85 (Neuroticism): acceptable for group research purposes. For the present sample, Cronbach's alpha reliability coefficients were $0.75,0.70,0.55,0.80$, and 0.68 , for Neuroticism, Extraversion, Openness to Experience, Conscientiousness, and Agreeableness, respectively.

\subsection{Data Analysis}

First, we reported means and standard deviations for each of the three dimensions of coaching behaviors. We also examined sex and age differences on the three subscales. Second, we reported inter-correlation coefficients among scores on the three dimensions of coaching behaviors. We also reported inter-correlation coefficients among scores on the Big-Five personality traits. Third, we reported Pearson correlation coefficients among scores on the three dimensions of coaching behaviors and scores on 
Table 1. Descriptive statistics, Cronbach alphas and intercorrelations.

\begin{tabular}{|c|c|c|c|c|c|c|c|}
\hline dimensions & $M$ & $S D$ & $\mathrm{~N}$ & Cronbach $\alpha$ & Assessing & Challenging & Supporting \\
\hline Assessing & 38.87 & 6.85 & 194 & 0.87 & 1 & & \\
\hline Challenging & 53.78 & 9.31 & 196 & 0.91 & $0.87^{\dagger}$ & 1 & \\
\hline Supporting & 72.49 & 11.36 & 195 & 0.92 & $0.80^{\dagger}$ & $0.88^{\dagger}$ & 1 \\
\hline
\end{tabular}

Note. ${ }^{\dagger} p<.01$.

the Big-Five personality traits. Finally, linear regression analysis was conducted separately with each of the three dimensions of coaching behaviors (Supporting, Assessing, and Challenging) as a dependent variable and the Big-Five personality traits as dependent variables.

\subsection{Results}

\subsubsection{Descriptive Analysis}

Means and standard deviations for the three dimensions of coaching behaviors are as follows: $M=71.31, S D=$ 10.71 for Supporting; $M=36.46, S D=6.09$ for Assessing; $M=53.98, S D=8.74$ for Challenging. No differences were statistically significant on the three dimensions (Supporting, Assessing, and Challenging) based on sex and age.

\subsubsection{Correlation Analysis}

Inter-correlation and correlation coefficients among scores on the three dimensions of coaching behaviors (Accessing, Challenging, and Supporting) and scores on the Big-Five personality traits (Neuroticism, Extraversion, Openness, Agreeableness, and Conscientiousness) are shown in Table 2. Scores on four of the five factors of personality (namely Extraversion, Openness, Agreeableness, and Conscientiousness) were significantly and positively related to those on the three dimensions of coaching behaviors, which confirms Hypotheses 1, 2, and 3. As expected, the score on Neuroticism was significantly and negatively related to scores on the three dimensions of coaching behaviors, which confirms Hypothesis 4 .

\subsubsection{Regression Analysis}

Since there are no significant differences in scores on the three dimensions of coaching behaviors and Big-Five personality traits based on sex and age, it is reasonable that sex and age was not entered as independent variables as well as the Big-Five personality traits when predicting each of the three dimensions of coaching behaviors.

Regressions results are reported in Table 3. As shown in Table 3, each of the three dimensions of coaching behaviors (Assessing, Challenging, and Supporting) can be significantly predicted by the Big-Five personality traits. The Big-Five personality traits can uniquely explain $24 \%, 28 \%$, and $24 \%$ total variance for Assessing,
Table 2. Correlations forchinese managerial coaching behaviors with Big-Five personality traits $(N=175)$.

\begin{tabular}{|c|c|c|c|c|c|c|c|c|}
\hline Scales & $\mathrm{Ac}$ & $\mathrm{Ch}$ & $\mathrm{Su}$ & $\mathrm{N}$ & E & $\mathrm{O}$ & A & $\mathrm{C}$ \\
\hline $\mathrm{Ac}$ & 1 & $0.81^{\dagger}$ & $0.77^{\dagger}$ & $-0.35^{\dagger}$ & $0.43^{\dagger}$ & $0.32^{\dagger}$ & $0.20^{\dagger}$ & $0.30^{\dagger}$ \\
\hline $\mathrm{Ch}$ & & 1 & $0.83^{\dagger}$ & $-0.34^{\dagger}$ & $0.37^{\dagger}$ & $0.33^{\dagger}$ & $0.23^{\dagger}$ & $0.45^{\dagger}$ \\
\hline $\mathrm{Su}$ & & & 1 & $-0.28^{\dagger}$ & $0.39^{\dagger}$ & $0.38^{\dagger}$ & $0.26^{\dagger}$ & $0.31^{\dagger}$ \\
\hline $\mathrm{N}$ & & & & 1 & $-0.62^{\dagger}$ & $-0.22^{\dagger}$ & $-0.52^{\dagger}$ & $-0.51^{\dagger}$ \\
\hline $\mathrm{E}$ & & & & & 1 & $0.28^{\dagger}$ & $0.34^{\dagger}$ & $0.41^{\dagger}$ \\
\hline $\mathrm{O}$ & & & & & & 1 & $0.25^{\dagger}$ & $0.30^{\dagger}$ \\
\hline A & & & & & & & 1 & $0.49^{\dagger}$ \\
\hline $\mathrm{C}$ & & & & & & & & 1 \\
\hline
\end{tabular}

$\overline{\text { Note. } * p<0.05,{ }^{\dagger} p<0.01 . \mathrm{Ac}=\text { Accessing, } \mathrm{Ch}=\text { Challenging, } \mathrm{Su}=\mathrm{Sup}-}$ porting, $\mathrm{N}=$ Neuroticism, $\mathrm{E}=$ Extraversion, $\mathrm{O}=$ Openness to experience, $\mathrm{A}$ $=$ Agreeableness, $\mathrm{C}=$ Conscientiousness .

Table 3. Regressions results (B) predicting accessing, challenging, and supporting from the Big-Five personality traits $(N=195)$.

\begin{tabular}{cccc}
\hline Scale & Assessing & Challenging & Supporting \\
\hline Neuroticism & -0.11 & -0.07 & 0.03 \\
Extraversion & $0.28^{\dagger}$ & $0.16^{\dagger}$ & $0.27^{\dagger}$ \\
Openness to Experience & $0.20^{\dagger}$ & $0.20^{\dagger}$ & $0.26^{\dagger}$ \\
Agreeableness & $-0.05^{\dagger}$ & -0.07 & 0.06 \\
Conscientiousness & 0.10 & $0.32^{\dagger}$ & 0.11 \\
$R_{\text {Total }}^{2}$ & 0.24 & 0.28 & 0.24 \\
$F$ & $10.6^{\dagger}$ & $13.0^{\dagger}$ & $10.9^{\dagger}$ \\
$d f$ & 5169 & 5169 & 5169 \\
\hline
\end{tabular}

Note. ${ }^{*} p<0.05 .{ }^{\dagger} p<0.01$..

Challenging, and Supporting, respectively. Specifically, Extroversion and Openness to Experience contributed significantly to the prediction of Assessing and Supporting; Openness to Experience and Conscientiousness contributed significantly to the prediction of Challenging; and Neuroticism and Agreeableness did not contribute significantly to the prediction of all the three dimensions of coaching behaviors. 


\section{Discussions}

This is one of few empirical studies on coaching in Mainland China. The two fold aims of the present research have been achieved. The first aim to develop a Chinese Managerial Coaching Behaviors Inventory was primarily achieved. Although we did not know most of the items in the Managerial Coaching Behaviors Inventory developed by Noer $[14,15]$, we followed the procedure of item generation recommended by Jackson [40] and the 46-item Chinese Managerial Coaching Behavior Inventory was self-compiled and developed based on Noer's Triangle Coaching Model [14,15]. Compared to Noer's Managerial Coaching Behaviors Inventory [29], the results showed the Chinese Managerial Coaching Behavior Inventory has higher internal consistency coefficients, which may be due to more items for each of the three dimensions of coaching behaviors. After an item comparison of this inventory with Noer's [29] inventory, it is found that items of this inventory cover almost all items of Noer's [29] inventory. However, there is a big difference that this inventory emphasizes on supervisor-subordinate interactions while Noer's inventory emphasizes coaching interactions between supervisors and subordinates. The development of Chinese Managerial Coaching Behavior Inventory has two implications for coaching practice: first, this inventory can be used as a measurement of managerial coaching behaviors before and after a coaching workshops course; second, this inventory provides a guideline for developing a coaching workshops course to enhance managers' coaching behaviors or skills.

The second aim to examine the relations between managerial coaching behaviors and Big-Five personality traits was also achieved. Results of Study Two showed that Extraversion, Openness to Experience, and Conscientiousness are good predictors of managerial coaching behaviors. There are two implications of this finding: first, if coaching turns out to be a key indicator of high performance and selection of managers as internal coaches is important, this finding helps. For example, the research results would suggest organizations select candidates with higher scores of Extraversion, Openness to Experience, and Conscientiousness. Second, there is evidence that personality traits can be significantly changed under interventions. For example, Piedmont [48] reported results in support of significant shifts in all the five personality traits from pre- to post-treatment in a 6-week program of intensive outpatient counseling. As such, managerial coaching behaviors may be enhanced by interventions changing personality traits.

There are at least three contributions of this research as follows: firstly, this research contributes to the current coaching literature which is dominated by westerners' research; secondly, the Chinese Managerial Coaching
Behaviors Inventory is a practical tool for managerial improvements in the Chinese context. Finally, this research provides us with a route to enhancing managerial coaching behaviors and assessing managerial coaching behaviors by personality traits.

There are at least five limitations to the present research. First, the sample size $(N=196)$ in Study One is small and the investigated firms are selected by convenience, which does not well represent a variety of firms such as one firm with a coaching workshops course. Managerial coaching behaviors may vary in different firms. Whether the Chinese Managerial Coaching Behaviors Inventory developed in the present research is generalizable to all kinds of firms and managers remains to be examined. Large sample size of participants with different kinds of firms should be used in the future research. Second, although Cronbach's alphas for the NEO-Five Factor Inventory were generally as expected, Cronbach's alpha (0.55) for Openness to Experience was very low. Results of Study Two that Openness to Experience is a good predictor for each of the three dimensions of coaching behaviors (Assessing, Challenging, and Supporting) may be questionable because of an unreliable subscale of Openness to Experience. More reliable NEO-Five Factor Inventory should be used in future research. Third, according to Jackson's [40] recommendations, limited work has been done and there is still quite a lot of work to be done in developing the Chinese Managerial Coaching Behaviors Inventory. For example, to test construct validity of this inventory, correlations need to be examined between managers' ratings of coaching behaviors and subordinates' ratings of their supervisors' coaching behaviors. Correlations also need to be examined between scores on this inventory and other managerial coaching behaviors inventories such as the Coaching Behaviors Instrument [6]. To test predictive ability of this inventory, relations need to be assessed between the three dimensions of coaching behaviors and other variables such as job performance, job satisfaction, and personal growth. More work should be done to test the reliability and validity of this measure in future research. Fourth, this inventory with 46 items may be too long for commercial or non-academic purposes. A shorter inventtory such as with 30 items or less is needed for convenience in assessing the three dimensions of coaching behaviors in the Chinese context. A more concise Chinese Managerial Coaching Behaviors Inventory should be developed in future research. Finally, we did not do a cultural comparison between Chinese Managerial Coaching Behaviors Inventory and Noer's (2005b) inventory due to lack of equivalence between these two inventories. Further research needs to address the cultural issues of coaching behaviors as when Noer (2007) compared Saudi Arabia with the US. 
After the above discussion, at least two conclusions can be summarized as follows:

1) Chinese Managerial Coaching Behaviors Inventory is a reliable and valid tool to assess Chinese managers' coaching behaviors.

2) Managerial coaching behaviors can be largely predicted by Big-Five personality traits.

\section{Acknowledgements}

Thanks goes to Dr. D.M Noer for providing us with the Managerial Coaching Behaviors Inventory for reference. Thanks also goes to those managers who participated in this research.

\section{REFERENCES}

[1] A. D. Ellinger, R. G. Hamlin and R. S. Beattie, "Behavioral Indicators of Ineffective Managerial Coaching: A Cross-National Study," Journal of European Industrial Training, Vol. 32, No. 4, 2008, pp. 240-257. http://dx.doi.org/10.1108/03090590810871360

[2] F. S. Salisbury, "Developing Managers as Coaches," McGraw-Hill Book Company, New York, 1994.

[3] J. W. Gilley and N. Boughton, "Stop Managing, Start Coaching: How Performance Coaching Can Enhance Employee Commitment and Improve Productivity," McGraw-Hill, New York, 1995.

[4] H. A. Fanasheh, "The Perception of Executive Coaching among CEOs of America's top 500 Companies," Unpublished Dissertation, Pepperdine University, Malibu, 2003.

[5] S.-W. Chen and Y.-L. Zhang, "The Influence of Executive Coaching on Employee Satisfaction and Turn Over," Modern Finance \& Economics, Vol. 28, 2008, pp. 56-60.

[6] G. N. McLean, B. Yang, M.-H. C. Kuo, A. S. Tolbert and C. Larkin, "Development and Initial Validation of an Instrument Measuring Managerial Coaching Skill," Human Resource Development Quarterly, Vol. 16, No. 2, 2005, pp. 157-178. http://dx.doi.org/10.1002/hrdq.1131

[7] A. D. Ellinger and R. P. Bostrom, "Managerial Coaching Behaviors in Learning Organizations," Journal of Management Development, Vol. 18, No. 9, 1999, pp. 752-771. http://dx.doi.org/10.1108/02621719910300810

[8] A. D. Ellinger, A. F. Ellinger and S. B. Keller, "Supervisory Coaching Behavior, Employee Satisfaction, and Warehouse Employee Performance: A Dyadic Perspective in the Distribution Industry." Human Resources Development Quarterly, Vol. 14, No. 4, 2003, pp. 438-458. http://dx.doi.org/10.1002/hrdq.1078

[9] M. A. Sullivan, "The Effectiveness of Executive Coaching in the Development of Emotional Intelligence Competencies," Unpublished Dissertation, Spalding University, Louisville, 2006.

[10] S. W. Kim, "Managerial Coaching Behavior and Employee Outcomes: A Structural Equation Modeling Analysis," Dissertation Abstracts International Section A: Humanities and Social Sciences, 2011, p. 662.
[11] K. T. W. Lam, "Managerial Coaching: Behaviors, the Measure, Antecedents and Outcomes," 2nd Edition, European Conference on Positive Psychology, University of Minho, Braga, 2007.

[12] C. R. Bell, "Managers as Mentors: Building Partnerships for Learning," 2nd Edition, Berrett-Koehler, San Francisco, 2002.

[13] A. M. Grant and M. J. Cavanagh, "The Goal-Focused Coaching Skills Questionnaire: Preliminary Findings," Social Behavior and Personality, Vol. 35, No. 6, 2007, pp. 751-760. http://dx.doi.org/10.2224/sbp.2007.35.6.751

[14] D. M. Noer, "Behaviorally Based Coaching: A CrossCultural Case Study," International Journal of Coaching in Organizations, Vol. 3, 2005, pp. 14-23.

[15] D. M. Noer, R. L. Christopher and V. Matthew, "Analysis of Saudi Arabian and U.S.Managerial Coaching Behaviors," Journal of Managerial Issues, Vol. 19, 2007, pp. 271-287.

[16] L. Marsh, "Good Manager: Good Coach? What Is Needed for Effective Coaching," Industrial and Commercial Training, Vol. 24, No. 9, 1992, pp. 3-8. http://dx.doi.org/10.1108/00197859210020213

[17] R. Kwiatkowski, "Inside-Out and Outside-In: The Use of Personality and 360 Degree Data in Executive Coaching," Karnac Books, London, 2006, pp. 153-181.

[18] A. Mansi, "Executive Coaching and Psychometrics: A Case Study Evaluating the Use of the Hogan Personality Inventory (HPI) and the Hogan Development Survey (HDS) in Senior Management Coaching," The Coaching Psychologist, Vol. 3, 2007, pp. 53-58.

[19] S. Carr, B. Cooke, L. Harris and B. Kendall, "Coaching with MBTI," In: J. Passmore, Ed., Psychometrics in Coaching: Using Psychological and Psychometric Tools for Development, Kogan Page, London, 2008, pp. 47-62.

[20] I. McCormick and G. S. J. Burch, "Personality-Focused Coaching for Leadership Development," Consulting Psychology Journal: Practice and Research, Vol. 60, No. 3, 2008, pp. 267-278.

http://dx.doi.org/10.1037/1065-9293.60.3.267

[21] J. L. Hughes, "Adjusting the Mirror: Strategies for Coaching Executives with Narcissistic Personality Features," Unpublished PhD dissertation, State University of New Jersey, New Brunswick, 2002.

[22] E. Nelson and R. Hogan, "Coaching on the Dark Side," International Coaching Psychology Review, Vol. 4, 2009, pp. 7-19.

[23] G. St. J Burch and N. Anderson, "Personality as a Predictor of Work-Related Behavior and Performance: Recent Advances and Directions for Future Research," In: G. P. Hodgkinson and J. K. Ford, Eds., International Review of Industrial and Organizational Psychology, Wiley, Chichester, 2008, pp. 261-305.

[24] R. B. Kaiser and J. Hogan, "Personality, Leader Behavior, and Overdoing it," Consulting Psychology Journal: Practice and Research, Vol. 63, 2011, pp. 219-242. http://dx.doi.org/10.1037/a0026795

[25] K. Tasa, G. J. Sears and A. C. H. Schat, "Personality and Teamwork Behavior in Context: The Cross-Level Moder- 
ating Role of Collective Efficacy," Journal of Organizational Behavior, Vol. 32, No. 1, 2011, pp. 65-85. http://dx.doi.org/10.1002/job.680

[26] L. J. Stewart, S. Palmer, H. Wilkin and M. Kerrin, "The Influence of Character: Does Personality Impact Coaching Success," International Journal of Evidence Based Coaching and Mentoring, Vol. 6, 2008, pp. 32-42.

[27] P. T. Costa and R. R. McCrae, "NEO PI-R Professional Manual," Psychological Assessment Resources, Odessa, 1992.

[28] G.-H. Chen and M.-Z. Chen, "Entrepreneur Coaching in China," Tsinghua University Press, Beijing, 2011.

[29] D. M. Noer, "Coaching Behavior Inventory: Participant Workbook," Noer Consulting, Greensboro, 2005.

[30] Confucius, "The Confucian Analects, the Great Learning \& the Doctrine of the Mean," Cosimo, New York, 2009.

[31] L. R. Bolton, L. K. Becker and L. K. Barber, "Big Five Trait Predictors of Differential Counter Productive Work Behavior Dimensions," Personality and Individual Differences, Vol. 49, No. 6, 2010, pp. 537-541. http://dx.doi.org/10.1016/j.paid.2010.03.047

[32] D. S. Chiaburu, I.-S. Oh, C. M. Berry, N. Li and R. G. Gardner, "The Five-Factor Model of Personality Traits and Organizational Citizenship Behaviors: A Meta-Analysis," Journal of Applied Psychology, Vol. 96, No. 6, 2011, pp. 1140-1166. http://dx.doi.org/10.1037/a0024004

[33] S. Clarke and I. T. Robertson, "A Meta-Analytic Review of the Big Five Personality Factors and Accident Involvement in Occupational and Non-Occupational Settings," Journal of Occupational and Organizational Psychology, Vol. 78, No. 3, 2005, pp. 355-376. http://dx.doi.org/10.1348/096317905X26183

[34] J. A. LePine and L. Van Dyne, "Voice and Cooperative Behavior as Contrasting forms of Contextual Performance: Evidence of Differential Relationships with Big Five Personality characteristics and cognitive ability," Journal of Applied Psychology, Vol. 86, No. 2, 2001, pp.326-336. http://dx.doi.org/10.1037/0021-9010.86.2.326

[35] S. V. Paunonen, "Big Five Factors of Personality and replicated Predictions of Behavior," Journal of Personality and Social Psychology, Vol. 84, No. 2, 2003, pp. 411422. http://dx.doi.org/10.1037/0022-3514.84.2.411

[36] S. V. Paunonen and M. C. Ashton, "Big Five Factors and Facets and the Prediction of Behavior," Journal of Personality and Social Psychology, Vol. 81, No. 3, 2001, pp. 524-539. http://dx.doi.org/10.1037/0022-3514.81.3.524

[37] M. R. Barrick and M. K. Mount, "The Big Five Personality Dimensions and Job Performance: A Meta-Analysis," Personnel Psychology, Vol. 44, No. 1, 1991, pp. 1-26. http://dx.doi.org/10.1111/j.1744-6570.1991.tb00688.x

[38] G. M. Hurtz and J. J. Donovan, "Personality and Job Performance: The Big Five Revisited," Journal of Applied Psychology, Vol. 85, No. 6, 2000, pp. 869-879. http://dx.doi.org/10.1037/0021-9010.85.6.869

[39] A. Aluja, Ó. García, L. F. García and N. Seisdedos, "Invariance of the 'NEO-PI-R' Factor Structure Across Exploratory and Confirmatory Factor Analyses," Personality and Individual Differences, Vol. 38, No. 8, 2005, pp. 1879-1889. http://dx.doi.org/10.1016/j.paid.2004.11.014

[40] D. N. Jackson, "A Sequential System for Personality Scale Development," In C. D. Spielberger, Ed., Current Topics in Clinical and Community Psychology, Academic Press, New York, 1970, pp. 61-96.

[41] F. M. Cheung, K. Leung and R. M. Fan, "Development of the Chinese Personality Assessment Inventory," Journal of Cross-Cultural Psychology, Vol. 27, No. 2, 1996, pp. 181-199. http://dx.doi.org/10.1177/0022022196272003

[42] F. M. Cheung and K. Leung, "Indigenous Personality Measures: Chinese Examples," Journal of Cross-Cultural Psychology, Vol. 29, No. 1, 1998, pp. 233-248. http://dx.doi.org/10.1177/0022022198291012

[43] A. M. Ryan and P. R. Sackett, "Pre-Employment Honesty Testing: Fakability, Reactions of Test Takers, and Company Image," Journal of Business and Psychology, Vol. 1, No. 3, 1987, pp. 248-256. http://dx.doi.org/10.1007/BF01020813

[44] P. R. Sackett, L. Burris and C. Callahan, "Integrity Testing for Personnel Selection: An Update," Personnel Psychology, Vol. 42, No. 3, 1989, pp. 491-529. http://dx.doi.org/10.1111/j.1744-6570.1989.tb00666.x

[45] L. F. Zhang and J. F. Huang, "Thinking Styles and the Five-Factor Model of Personality," European Journal of Personality, Vol. 15, No. 6, 2011, pp. 465-476. http://dx.doi.org/10.1002/per.429

[46] Y. F. He, "The Roles of Thinking Styles in Learning and Achievement among Chinese University Students," Unpublished Ph.D. Dissertation, University of Hong Kong, 2005.

[47] G. H. Chen and D. Watkins, "Stability and Correlates of Student Evaluations of Teaching at a Chinese University," Assessment \& Evaluation in Higher Education, Vol. 35, No. 6, 2010, pp. 675-685. http://dx.doi.org/10.1080/02602930902977715

[48] R. L. Piedmont, "Cracking the Plaster Cast: Big Five Personality Change during Intensive Outpatient Counseling," Journal of Research in Personality, Vol. 35, No. 4, 2001, pp. 500-520. http://dx.doi.org/10.1006/jrpe.2001.2326 